\title{
Los privilegios: justificación para la oposición leal y para los rebeldes en sus acciones contra la política de Felipe II en Flandes (1559-1581)
}

The Privileges: justification for the loyal opposition and the actions of the rebels against the

Philip the $2^{\text {nd' }}$ policy in Flanders (1559-1581)

\section{Prof. dr. Gustaaf Janssens ${ }^{1}$}

KU Leuven

Resumen: Durante la guerra de Flandes, el respeto de los privilegios era muy sensible, tanto en Brabante, como en el resto de los territorios. Por lo tanto, tanto el rey como sus gobernadores manifestaron con frecuencia que no querrían nada más que observar los privilegios. Esas declaraciones no pudieron convencer a la oposición leal, ni a los rebeldes que reclamaron las antiguas libertades. La defensa de los privilegios por los grupos políticos de los Países Bajos se situaba en la zona de tensión que fue el resultado del enfrentamiento de una administración estatal moderna y central con un orden social y político tradicional y feudal.

Palabras clave: Países Bajos; privilegios; Alegre Entrada; Felipe II; duque de Alba; Luis de Requesens; Guillermo de Orange; Joaquín Hopperus; oposición leal; rebelión.

Abstract: During the Dutch Revolt, respect for the privileges was an important issue, both in Brabant and in the other territories. Therefore, the King as well as the governors repeatedly declared that respecting the privileges, also to them, was a major concern. However, these declarations did not impress the loyal opposition nor the rebels, as both appealed to the old liberties. The political actors' defence of the privileges took place in an area of tension caused by the clash between a modern centralized (state) government and a feudal society based on political traditions.

${ }^{1}$ https://orcid.org/0000-0002-1948-8902

(C) 2018 Philostrato. Revista de Historia y Arte 


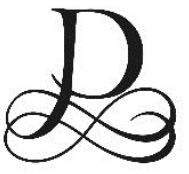

esde los inicios de la guerra de Flandes, la reclamación del respeto de los privilegios fue una constante. Así, Nicolette Mout señala que "desde 1568 los rebeldes se han referido a la conocida teoría del contrato, en que los privilegios eran en realidad acuerdos entre los gobernantes y los súbditos; acuerdos que fueron confirmados bajo juramento por ambas partes"2. Más tarde, en el discurso de los rebeldes, referirse a los privilegios se convirtió en un lugar común. Los historiadores Geoffrey Parker y Henk van Nierop sugieren que la oposición temprana a la política de Felipe II tiene sus raíces en la defensa de los privilegios locales. Si el soberano infringía su juramento, entonces - tal y como era generalmente aceptado - los súbditos quedaban liberados de su deber de obediencia ${ }^{3}$.

Para tratar sobre esta cuestión, en este artículo me he guiado por dos preguntas: $1^{\circ}$ ¿En qué circunstancias la oposición en los Países Bajos reclamó la Alegre Entrada ("Blijde Inkomst" o "Joyeuse Entrée") y otros privilegios entre 1559 y 1581 ? y de $2^{\circ}$ ¿Cuándo y en qué contexto los rebeldes reclamaron los privilegios? A partir de estas dos preguntas se puede observar que hago una distinción entre la reclamación "ordinaria" de privilegios - que yo llamaría "vigilancia de los privilegios" y, en algunos casos, la "oposición leal" - $y$, en segundo lugar, la reclamación de privilegios por personas o instituciones que optaron por la revuelta armada contra Felipe II.

\section{La oposición leal}

Un punto importante en la primera oposición contra el régimen de Felipe II fue la adopción de la nueva división diocesana de los Países Bajos en 1559. En esta cuestión, la Alegre Entrada fue reclamada desde el principio. En 1562, los brabanzones enviaron una delegación a Felipe II, advirtiendo al monarca que la incorporación de las abadías brabanzonas en los obispados iba en contra de la Alegre Entrada, el texto sobre el cual prestaba juramento cada nuevo príncipe en Brabante al inicio de su gobierno, y mediante el cual se

\footnotetext{
2 Nicolette Mout, "Van arm vaderland tot eendrachtige republiek. De rol van politieke theorieën in de Nederlandse Opstand", Bijdragen en Mededelingen betreffende de Geschiedenis der Nederlanden, 101, (1986), p. 357.

3 Henk Van Nierop, "Alva's Throne: Making Sense of the Revolt of the Netherlands", en The Origins and Development of the Dutch Revolt, comp. Graham Darby, (Londres-Nueva York: Routledge, 2001), p. 45; Geoffrey Parker, España y la rebelión de Flandes (Madrid: Nerea, 1989), pp. $11-12$, y 34.
} 
comprometía a respetar los privilegios de los súbditos ${ }^{4}$. Esta misma reclamación también había sido utilizada por la oposición de los abades de Brabante en 1519-1520 contra la política comendataria de Carlos V. Con arreglo al art. 63 de la Alegre Entrada de Carlos V en 1515, una abadía brabanzona nunca podía entregarse in commendam. Esta disposición se recoge en el artículo 56, en el texto de 1549 cuando el príncipe Felipe juraba fidelidad a los privilegios en el momento de su propia Alegre Entrada ${ }^{5}$. El consejero Joaquín Hopperus entendió bien que la protesta contra las nuevas diócesis atañía, en gran parte, al respeto de los privilegios, pues lo indicaba claramente en sus recomendaciones para llevar la paz a los Países Bajos cuando el duque de Alba llegó a dichas tierras ${ }^{6}$.

La oposición a las nuevas diócesis y a la promulgación de los decretos de Trento también fue impulsada por el temor de que en Brabante se introdujera una inquisición "al modelo español". La introducción de tal inquisición también iba en contra de los privilegios de los brabanzones, y fue este punto sobre el que en 1566 las ciudades de Bruselas, Lovaina, Amberes y Bolduque ('sHertogenbosch) presentaron su petición ante el Consejo de Brabante?.

A todo esto, se añadiría el hecho de que en el momento de la llegada del duque de Alba a los Países Bajos se produjo una gran conmoción en las ciudades en relación con el alojamiento de las tropas que le acompañaban. En virtud de ello, Margarita de Parma se declaró a sí misma, y de forma expresa, defensora de los privilegios de las ciudades ${ }^{8}$. Su acción estuvo claramente motivada por su descontento con la llegada del duque de Alba, así como por el hecho de que había perdido la confianza del rey ${ }^{9}$

Esta cuestión nos indica como desde la llegada del duque de Alba a los Países Bajos se oyeron duras críticas con respecto a sus acciones por no

\footnotetext{
4 Michel Dierickx, De oprichting van de nieuwe bisdommen in de Nederlanden onder Filips II (1559-1570), (Amberes-Utrecht: Uitgeverij Standaard Boekhandel-Het Spectrum, 1950), 160161. Véase también: Adrianus Clemens Johannes De Vrankrijker, "Het beroep op de Blyde Inkomste en andere privileges in Brabant tegen de inquisitie en de nieuwe bisdommen in de XVIe eeuw", Historisch Tijdschrift, 15, (1936), pp. 101-137.

5 Pieter Gorissen, De prelaten van Brabant onder Karel V (1515-1544). Hun confederatie (1534-1544). Standen en Landen-Anciens Pays et Assemblées d'Etats, 6, (Lovaina: Nauwelaerts, 1953), pp. 20-21.

6 Joaquín Hopperus, "Mémorial touchant le redresssement des affaires des Pays Bas, fait pour le service de Sa Majesté et à tréshumble correction dicelle" [¿agosto 1567?], Archivo General de Simancas (AGS), Secretaría de Estado (Estado), leg. 531, fo 55.

7 Gustaaf Janssens, 'Brabant in het Verweer'. Loyale oppositie tegen Spanje's bewind in de Nederlanden van Alva tot Farnese. 1567-1578. Standen en Landen-Anciens Pays et Assemblées d'États, 89, (Kortrijk-Heule: UGA, 1989), pp. 116-117.

8 Miguel de Mendivil, contador de artillería del ejército de Flandes, a Felipe II, 10-9-1567: Colección de Documentos inéditos para la Historia de España (CODOIN). eds. Martín Fernández Navarrete, Miguel Salvá \& Pedro Sainz de Baranda, 4, (Madrid: La viuda de Calero, 1844), p. 422.

${ }^{9}$ Gustaaf Janssens, "De ordonnantie betreffende de pacificatie van de beroerten te Antwerpen (24 mei 1567): breekpunt voor de politiek van Filips II ten overstaan van de Nederlanden", Handelingen van de Koninklijke Commissie voor de uitgave der Oude Wetten en Verordeningen van België - Bulletin [de la] Commission royale pour la Publication des anciennes Lois et Ordonnances de Belgique, 50, (2009), pp. 105-132.
} 
respetar la Alegre Entrada. El 9 de noviembre de 1567, Maximilien Morillon, vicario general del arzobispado de Malinas, en una carta enviada a su arzobispo el cardenal Granvela en relación con el Consejo de los Tumultos, estableció que "la Alegre Entrada estaba dormida"10.

Sin embargo, esta no fue el único caballo de batalla. La interminable negociación sobre la aceptación de las "peticiones" (es decir los impuestos que se llaman "beden" en néerlandes, o "aides" en francés) se convirtió en una fuente constante de molestias y enojos para el duque de Alba. De ahí proviene la reforma fiscal que propuso a finales de marzo de 1569, con los famosos nuevos impuestos conocidos como el Décimo y el Vigésimo Dinero. Esos impuestos tendrían la intención de sustituir a las peticiones, sobre la base de los principios de igualdad y capacidad, y su cobro no se arrendaba. Además, eran impuestos permanentes que tenían el fin de garantizar que el soberano ya no fuera dependiente de los fondos procedentes de España, ni de la voluntad de los súbditos ${ }^{11}$.

El Décimo y el Vigésimo Dinero desataron una ola de protestas, seguidas por una dura oposición. Esta oposición disgustó mucho al duque de Alba, que se enojó notablemente cuando se supo que a mediados de noviembre de 1571 la ciudad de Lovaina todavía no había organizado la recaudación del Décimo ${ }^{12}$. En su oposición, así se lo escribió el duque de Alba al rey, "los Estados acabaron con condiciones y libertades del pasado". Según él, esta postura fue la que, en los últimos años, causó tanto la rebelión como la decadencia de la religión. A pesar de que los privilegios irritaban al duque de Alba, este también vio que el recorte de las libertades podría poner en peligro la lealtad de los súbditos al monarca. Según él, era necesario encontrar un camino intermedio que tuviera en cuenta tanto la reputación como la autoridad del rey ${ }^{13}$.

El respeto por el monarca era mencionado también por los propios flamencos, como así hicieron cuando a finales de 1571 los Estados de Brabante decidieron enviar una delegación a España para protestar directamente ante Felipe II contra el Décimo Dinero, y que el gobernador intentó impedirlo. De acuerdo con la Alegre Entrada, los brabanzones tenían

10 "La joyeuse entrée dort", M. Morillon al cardenal Granvela, 9-11-1567: Correspondance du Cardinal de Granvelle, 1565-1583. ed. Edouard Poullet, 3, (Bruselas: Commission royale d'Histoire, 1881), p. 88.

${ }^{11}$ Ferdinand Grapperhaus, "El décimo de Alba en los Países Bajos. Un fracaso de importantes consecuencias", en Banca, Crédito y capital. La Monarquía Hispana y los antiguos Países Bajos (1505-1700). comp. Carmen Sanz Ayán y Bernardo J. García García, (Madrid: Fundación Carlos de Amberes, 2006), pp. 156-157. Véase también Ferdinand Grapperhaus, Alva en de Tiende Penning, (Zutphen: De Walburg Pers-Kluwer, 1982), y Gustaaf Janssens, "De Tiende Penning van Alva: factor van goed bestuur en catalysator van verzet en opstand in de Nederlanden", Eigen Schoon \& De Brabander, 91, (2008), pp. 17-50.

${ }^{12}$ Stadsarchief Leuven [Archivos comunales de Leuven, Bélgica] (ACL), Fondo antiguo, $\mathrm{n}^{\circ} 301$, fo $109 v^{\circ}$

13 Gustaaf Janssens, "The Duke of Alba: Governor of the Netherlands in Times of War", en Alba. General and Servant to the Crown. Comps. Maurits Ebben, Margriet Lacy-Bruijn, y Rolof van Hövelle tot Westerflier, (Rotterdam: Karawansaray Publishers, 2013), p. 105. 
el derecho de dirigirse directamente al monarca ${ }^{14}$. En la época de Carlos $V$ ya había surgido un conflicto entre los Estados y la gobernadora Margarita de Austria con respecto al contacto inmediato con el monarca, pero este derecho fue confirmado de manera explícita por Carlos $V$ en 1526 y también se encuentra en el texto de la Alegre Entrada de $1549^{15}$.

Este hecho nos indica como los brabanzones supervisaron estrictamente el respeto de los privilegios en todos los ámbitos de la vida pública. Ejemplos de tal "vigilancia" se encuentran tras su actuación al ser publicadas las ordenanzas en los Países bajos por el gobernador y el consejo privado bajo la autoridad del rey. El 11 de diciembre de 1571, los prelados y los nobles de Brabante discutieron sobre la ordenanza del 23 de julio de dicho año, relativa a la caza, así como otras que consideraban que ciertas disposiciones fueron contradictorias con lo determinado en la Alegre Entrada. De este modo, el 17 de diciembre del mismo año de 1571 mostraron su preocupación al respecto a Charles de Berlaymont, que se encargó de explicarlo todo al duque de Alba. El mismo día, los Estados de Brabante recordaron la obligación de que, según la Alegre Entrada, para ejercer como funcionario en Brabante era necesario ser brabanzón. Además, todos los funcionarios de Brabante tenían que prestar juramento a la Alegre Entrada, so pena de expulsión ${ }^{16}$.

La "naturaleza brabanzona" siguió siendo un punto de atención especial para los brabanzones. Los comandantes de los castillos de Brabante debían ser brabanzones, lo que también era válido para los gobernadores de las ciudades $y$, por supuesto, para todos los funcionarios. En un parecer enviado el 28 de octubre de 1574 a Felipe II, Joaquín Hopperus señaló al rey la importancia de ese hecho, e informó sobre cómo se podría afrontar esta problemática ${ }^{17}$.

Al duque de Alba le irritaban los privilegios, según él totalmente obsoletos, a los cuales se hacía referencia en los Países Bajos y que la oposición invocaba constantemente. También quería desarrollar un nuevo orden político y social que fuese aplicable de manera general y que, para él, fuera justo. Quería "crear un nuevo mundo", tal y como se lo escribió al rey. El duque de Alba creía que en los Países Bajos "no existía justicia y que la Alegre Entrada era una de las causas"18.

En este sentido, el duque de Alba era un buen gobernador que quería acabar con la corrupción y la arbitrariedad. Por este motivo, deseaba que fuese vigente una legislación uniforme en todo el territorio de los Países

\footnotetext{
${ }^{14}$ Joaquín Hopperus a Felipe II, 14-5-1572, AGS, E., leg. 551, f० 20.

15 Helmut Georg Koenigsberger, Monarchies, States Generals and Parliaments. The Netherlands in the Fifteenth and Sixteenth Centuries, (Cambridge: University Press, 2001), p. 121 y Gorissen, De prelaten, pp. 50-51.

${ }_{16} \mathrm{ACL}$, Fondo antiguo, $\mathrm{n}^{\circ} 301$, ffo $134 \mathrm{v}^{\circ}-135 \mathrm{r}^{\circ}$, y ffo $150 \mathrm{r}^{\circ}-151 \mathrm{v}^{\circ}$.

17 "Primer recuerdo de J. Hopperus. A su Magestad sobre la pacificación de los Estados Baxos. Diolo en Madrid a 28 de octubre 1574", AGS, E., leg. 559, f० 78.

18 Janssens, "The Duke of Alba", pp. 107 y 397, nota 158.
} 
Bajos, y quería aportar claridad al derecho consuetudinario local y codificarlo ${ }^{19}$. También investigó la base jurídica de los privilegios urbanos. Para ello, en 1570 pidió al gobierno municipal de Lovaina el texto del privilegio con el cual la ciudad había obtenido el derecho, otorgado el 14 de septiembre de 1378 por los duques Johanna y Wenceslao, de elegir a sus concejales ${ }^{20}$.

Así mismo, en 1570, el duque de Alba llevó a cabo una profunda reforma del derecho penal con las ordenanzas del 5 y 9 de julio. En este contexto, los brabanzones estaban alerta, y en noviembre de 1570 la ciudad de Lovaina se preguntó si determinadas disposiciones de las "ordenanzas criminales" no iban en contra de los privilegios. Al parecer, después de consultar a las autoridades municipales de Bruselas y de Bolduque, la sospecha de Lovaina no estaba justificada21.

El 15 de mayo de 1573, el duque de Alba resumió sus objeciones contra el estado de los privilegios en ese momento en una larga declaración que se elaboró como resultado de la reforma del Consejo de los Tumultos. El duque señalaba explícitamente que los delitos de rebelión y de lesa majestad estaban reservados al monarca. En la memoria, el gobernador también se quejaba del hecho de que en muchos pueblos y ciudades de los Países Bajos existieran "peculiares costumbres con respecto a la justicia y la confiscación"22.

Luis de Requesens, el noble catalán que fue nombrado gobernador general de los Países Bajos a fines de 1573, estaba en desacuerdo en varios puntos con la política de su predecesor, pues deducía que dicha acción era funesta y quería acabar con el descontento con respecto al gobierno. A diferencia del duque de Alba, Requesens no estaba convencido de que la cuestión de la religión fuera la raíz de los problemas en los Países Bajos, y expresaba su deseo de querer "ganarse los corazones de los súbditos". Por lo tanto, no es sorprendente que el 11 de junio de 1574, Luis de Requesens, pocos meses después de la salida del duque de Alba, declarase expresamente ante los Estados Generales que respetaría los privilegios ${ }^{23}$.

19 Michel Dierickx, "Nieuwe gegevens over het bestuur van de hertog van Alva in de Nederlanden", Bijdragen tot de Geschiedenis der Nederlanden, 18, (1963-1964), p. 188.

$20 \mathrm{ACL}$, Fondo antiguo, $\mathrm{n}^{\circ} 300$, ffo $259 \mathrm{v}^{\circ}-260 \mathrm{r}^{\circ}$, fo $280 \mathrm{r}^{\circ}$, y fo $396 \mathrm{v}^{\circ}$.

$21 \mathrm{ACL}$, Fondo antiguo, $\mathrm{n}^{\circ} 300$, ff $318 \mathrm{v}^{\circ}-322 \mathrm{v}^{\circ}$. En cuanto a las "ordenanzas criminales", Janssens, "The Duke of Alba", pp. 107-108, Marijke Van der Vrugt, De criminele ordonnantiën van 1570. Enkele beschouwingen over de eerste strafrechtcodificatie in de Nederlanden, (Zutphen: De Walburg Pers, 1978).

22 "Relación sumaria de los proçessos remitidos por el duque de Alba a los consejeros provinciales de los Estados Baxos y de otros negoçios dellos dependientes", Nimega, 15-51573, AGS, E., leg. 555, fo 106.

23 Violet Soen, Vredehandel. Adellijke en Habsburgse verzoeningspogingen tijdens de Nederlandse Opstand (1564-1581), (Amsterdam: University Press, 2012), p. 101. Véase también "Relación de que los diputados de los Payses Baxos juntados en Bruselas por orden del Comendador Mayor le propusieron çerca de la pacificaçión de los dichos Payses [8-6-1574], AGS, E., leg. 568, fo 90. 
Ése anhelo llegó a Madrid, donde fue propagado en repetidas ocasiones (por ejemplo, en 1574 y en 1575) por el consejero Hopperus como remedio para la pacificación de los Países Bajos, indicando que era necesario poner en práctica el gobierno de los Países Bajos "como antes". Es decir, como en la época de Carlos V, con un gobernador de sangre real, y con respeto a los privilegios ${ }^{24}$, idealizando dicho periodo, aunque no se llegó a poner en práctica en esos momentos.

Tras la muerte de Luis de Requesens el 5 de marzo de 1576, se extendió el rumor de que el Consejo de Estado se haría cargo del gobierno de los Países Bajos. Sin embargo, los Estados de Brabante deseaban que los Estados nombraran a un nuevo gobernador, para lo cual elaboraron argumentos con los cuales intentaban demostrar que tenían derecho a designar a un "ruwaert" (es decir un 'gobernador-protector'). Este esfuerzo de Brabante para nombrar por su cuenta un gobernador interino, sin duda encajaba con la intención de dar énfasis a la importancia de los privilegios. Sin embargo, el Consejo de Estado se hizo de facto con el gobierno del país y no se llevó a cabo el nombramiento de un "ruwaert" por los Estados 25 .

De hecho, el 24 de marzo de 1576, Felipe II nombró al Consejo de Estado como gobernador interino. Este consejo de gobierno declaró el 22 de mayo de 1576 en una carta al rey que llevaría la paz a los Países Bajos y que perseguiría la restauración del gobierno "como antes", así como la conservación de los privilegios ${ }^{26}$. A partir de septiembre de ese año, la política de los Países Bajos experimentó un impulso vertiginoso. Los Estados de Brabante instaron, junto con los de Hainaut, sin tener potestad para ello, en reunir a los Estados Generales y argumentaron que era su deber llevar la paz y la armonía al país. Aproximadamente al mismo tiempo que se mantenía el debate sobre este asunto, el 8 de noviembre de 1576, que dio lugar a la Pacificación de Gante, don Juan de Austria, hermanastro de Felipe II, Ilegó a los Países Bajos como nuevo gobernador. Después de unas difíciles negociaciones con los Estados, don Juan reconoció la Pacificación de Gante, pero su gobierno se inició en una atmósfera de desconfianza total. Cuando, el 8 de septiembre de 1577, los Estados se opusieron a don Juan y lo declararon incompetente para el gobierno, suscitaron la cuestión de la Alegre Entrada en una declaración intitulada Discourssommier des iustes causes et raisons $(\ldots)^{27}$.

\footnotetext{
24 Joaquín Hopperus a Felipe II, 9-10-1574, AGS, E., leg. 559, fo 77 ("La verdadera pacificación de los Payses Baxos"). Véase también Janssens, "Brabant in het Verweer", p. 246, y "Las cosas que paresçe devría conçeder su Magestad a los xv stados no rebelados de los Payses Baxos" (art. 2), [19-6-1575], (AGS, E., leg. 559, fo 84).

25 Janssens, "Brabant in het Verweer", pp. 170-175.

${ }^{26}$ El Consejo de Estado en Flandes a Felipe II, 22-5-1576: Correspondance de Philippe II sur les affaires des Pays-Bas, ed. Louis-Prosper Gachard, (Bruselas: C. Muquardt, 1861), IV, pp. 154-155.

27 Pieter Antoon Marie Geurts, "Het beroep op de Blijde Inkomste in de pamfletten uit de Tachtigjarige Oorlog", Standen en Landen - Ancien Pays et Assemblées d'État, 16, (1958), p. 9, e Id., De Nederlandse Opstand in de pamfletten 1566-1584, (Utrecht: HES Publishers,
} 
Es en este contexto que Philippe de Marnix, señor de Sainte-Aldegonde, defendió en la Dieta de Worms (1578) el nombramiento del archiduque Matías como nuevo gobernador de los Países Bajos. El señor de Sainte-Aldegonde también alegó que, dado el Gran Privilegio de María de Borgoña (1477), la Alegre Entrada de Brabante era aplicable a todas las provincias de los Países Bajos. Esta tesis también fue defendida inicialmente por los delegados de los Estados Generales en las negociaciones de paz en Colonia en 1579, pero en última instancia no fue aceptado ${ }^{28}$.

Una vez que don Juan inició su contraataque, pudo tomar diversas ciudades $y$, cuando en 1578 se hizo con el control de una gran parte de Brabante y de Hainaut, confirmó que respetaría los privilegios en los Países Bajos. Claro está, que dicha declaración debía servir para inspirar confianza y convencer a la oposición leal para llegar a una reconciliación con el monarca ${ }^{29}$.

\section{Los privilegios en el discurso de los rebeldes}

Está claro que desde 1568 en los panfletos, los autores afines a la revuelta buscaban su motivación en una interpretación de la Alegre Entrada según el derecho natural, lo que provocó que el derecho natural se convirtiera en el fundamento del derecho político. Dicha cuestión quedó clara cuando en 158185 se estableció que era posible deshacerse de un tirano. En los panfletos afines a la revuelta y publicados entre 1565 y 1572, se hacía referencia principalmente al hecho de que las ordenanzas tocantes a la religión y la Inquisición eran contrarias a las disposiciones de la Alegre Entrada ${ }^{30}$. No obstante, para las personas que fueron citadas en el Consejo de los Tumultos y que fueron condenadas por alta traición o por delito de lesa majestad, los privilegios no eran aplicables ${ }^{31}$. La idea de que la herejía estaba equiparada con el delito de lesa majestad, era una idea ampliamente aceptada por los juristas en el siglo XVI. La ordenanza del 25 de agosto 1566 también establecía que las personas responsables del iconoclasmo y de otros actos de violencia serían consideradas culpables como "...sacrilèges, larons, publicques

1978), pp. 66-67. En cuanto al contexto histórico del panfleto: Janssens, "Brabant in het Verweer", pp. 330-348.

28 Geurts, "Het beroep op de Blijde Inkomste", pp. 9-12; Mout,"Van arm vaderland", p. 356. En cuanto a la conducta de Philippe de Marnix de Sainte-Aldegonde en la Dieta de Worms, Monique Weis, Philippe de Marnix et le Saint-Empire (1566-1578). Les connections allemandes d'un porte-parole et la révolte des Pays-Bas, Collection des Études historiques, 10, (Bruselas: Société royale d'Histoire du Protestantisme belge, 2004), pp. 40-52.

29 Monica Stensland, Habsburg Communication in the Dutch Revolt, (Amsterdam: Amsterdam University Press, 2012), p. 96.

30 Geurts, De Nedelandse Opstand, pp. 148-50.

31 Willem Van Iterson,Geschiedenis der confiscatie in Nederland. Een rechtshistorische studie aan de hand van Noord-Nederlandse, een aantal Zuid-Nederlandse en andere bronnen, (Utrecht: De Vroede, 1957), p. 97, y James D. Tracy, "Heresy Laws and centralization under Mary of Hungary: Conflict between the Council of Holland and the Central Government over the Enforcement of Charles V's Placards", Archiv für Reformationsgeschichte, 73, (1982), pp. 285-86. 
ennemy de Dieu, de nous et du monde, lesquelz permectons à nous à tuer non seullement inpunément, mais aussy avec honneur comme l'on faict d'ung ennemy commung de la patrie, et grassateur publicque" ${ }^{\prime 32} .0$, dicho en otras palabras: merecían todos la pena capital.

En un comentario sobre la Petición de los Nobles Confederados ( 5 de abril de 1566), Gilles Le Clercq hizo referencia al hecho de que el rey, debido a la Alegre Entrada, estaba obligado a aceptar peticiones por escrito. Por otra parte, el mismo autor se centraba en las ordenanzas como en contra de los privilegios que se garantizaban en la Alegre Entrada ${ }^{33}$.

En 1567 apareció el panfleto Vraye narration et apologie des choses passées au Pays-Bas, touchant le fait de la religion (...). Es un texto anónimo, pero el autor es - ya se ha confirmado - el citado Philippe de Marnix, señor de Sainte-Aldegonde, famoso humanista calvinista, que fue posteriormente secretario del príncipe de Orange ${ }^{34}$. En el tratado, el autor se refiere a los acontecimientos del año 1566 - el famoso "Año de las Maravillas o "Wonderjaar" -, defendiendo la Petición de los Nobles y estableciendo que la Alegre Entrada "otorga el derecho a los súbditos de poner fin a la obediencia a aquella parte que no cumple con sus obligaciones" 35 .

Igualmente, en los escritos que aparecen en 1568 bajo su nombre, Guillermo de Orange establecía sin rodeos que se ha infringido la Alegre Entrada. Así lo afirma en su Waerschowinghe ...aen de inghesetenen ende ondersaten van den Nederlanden, indicando que los Países Bajos siempre debían regirse de acuerdo con los privilegios y las libertades. Según Orange, el monarca y sus súbditos también estaban vinculados "por un contrato y por un juramento" ("by formelen contracte ... ende ooc by solemnelen eede ...") ${ }^{36}$. Por su parte, en su declaración Verklaringhe ende Uutschrift comentaba que la acción del duque de Alba iba en contra de lo que el rey había prometido ${ }^{37}$. Por último, en la respuesta a su citación en el Consejo de los Tumultos (Antwoorde opte brieven van Dagement ...), el príncipe hacía referencia

32 Aline Goosens, Les inquisitions modernes dans les Pays-Bas méridionaux 1520-1633, (Bruselas : Éditions de l'Université de Bruxelles, 1997), I, pp. 102-103. La edición del texto en Jan Baptiste Christyn, Placcaeten, ordonnantien, landt-charters, privilegien, ende instructien by de Princen van dese Neder-Landen uytghegheven (...), (Bruselas: Huybrecht Antoon Velpius, 1664), III, pp. 21-22.

33 Geurts, "Het beroep op de Blijde Inkomste", pp. 4-5.

34 Geurts, De Nederlandse Opstand, p. 34.

35 Adrianus Clemens Johannes De Vrankrijker, De motiveering van onzen opstand. De theorieën van het verzet der Nederlandsche opstandelingen tegen Spanje in de jaren 15651581, (Nimega-Utrecht: Dekker \& Van de Vegt, 1933), pp. 34-41.

36 Geurts, De Nederlandse Opstand, p. 151 y Verantwoordinge, verklaringhe ende waerschouwinghe mitsgaders eene hertgrondighe begheerte des edelen, lancmoedighen ende hooghgeboren Princen van Oraengien. Naar de eerste drukken van 1568 opnieuw uitgegeven. Ed. Magdalena Geertruida Schenk, (Amsterdam: Wereldbibliotheek, 1933), p. 120.

37 Geurts, "Het beroep op de Blijde Inkomste", p. 67, y Verantwoordinge, p. 104. 
expresa a la convención y al tratado celebrados en virtud de la Alegre Entrada ("de conventien ende verdraghe, ghemaectby der blijder incoemste") ${ }^{38}$.

Del mismo modo, cuando en 1572 varias ciudades y regiones de Holanda y Zelanda se rebelaron, y los Estados de Holanda se reunieron por iniciativa propia y organizaron después la administración en sus territorios, la defensa de los privilegios desempeñó un papel importante en su discurso. En este contexto, Philippe de Marnix presentó a la reina Isabel de Inglaterra una memoria en la cual sostenía que el príncipe de Orange tenía el derecho de resistencia contra el monarca ${ }^{39}$. Por su parte, en el mismo año de 1572 , los Estados de Holanda elaboraron una relación de privilegios que según ellos fueron pisoteados por "la tiranía española"40.

Que la interpretación del derecho de resistencia de los rebeldes durante la Guerra de Flandes cada vez era más concreta, lo demuestra Johannes Junius Jr., gobernador de Veere en 1574, en el tratado Sekere brieven waerinne den aenghevangen Vrede-Handel (...) vervaetet is (...), tratado en el cual conecta el derecho de oposición y la teoría del contrato con el Soberano con "una cierta concepción de la soberanía popular, basada en el derecho natural, con la cual el pueblo, por su propia voluntad, había otorgado el poder al príncipe". Según Junius "un acuerdo entre el monarca y el pueblo como la ya citada Alegre Entrada, no era otra cosa que una expresión del derecho natural en la forma del derecho positivo"41.

Cuando los Estados Generales y el Consejo de Estado firmaron un acuerdo con don Juan de Austria (el Ilamado "Edicto Perpetuo" del 12 de febrero de 1577), Guillermo de Orange y los Estados de Holanda y de Zelanda mostraron su desconfianza. El príncipe de Orange no quiso firmar el Edicto porque, según él "los privilegios son recortados"42.

Esta cita nos demuestra como Orange continuó motivando sus acciones invocando la Alegre Entrada. En su Apología de 1581, afirma que el duque de Brabante, es decir, el rey Felipe II, había "miles de veces" violado los artículos de la Alegre Entrada. Por lo tanto, el monarca fue acusado por el dicho Príncipe "de perjurio, deslealtad y rebelión" contra el país ${ }^{43}$. En la Declaración de Abjuración de los Estados Generales ("Plakkaat van Verlatinge"), también del mismo año de 1581, no se menciona la Alegre Entrada, pero sí está presente en la mente de los redactores. De hecho, en la introducción, se hace

\footnotetext{
38 Herman De la Fontaine Verwey, "De Blijde Inkomste en de opstand tegen Filips II", Standen en Landen -Anciens Pays et Assemblées d'États, 19, (1960), p. 109, y Verantwoordinge, p. 95.

39 Mout, "Van arm vaderland", p. 353.

40 Parker, España y la rebelión de Flandes, p. 12.

41 Mout, "Van arm vaderland", p. 358, y Geurts, De Nederlandse Opstand, pp. 52-53.

42 Janssens, "Brabant in het Verweer", pp. 330-332.

43 De la Fontaine Verwey, "De Blijde Inkomste", p. 115.
} 
referencia al derecho de los súbditos de "sustituir un Príncipe tiránico por otro Señor"44.

La batalla en defensa de los privilegios se situaba en la zona de tensión que fue el resultado del enfrentamiento de una administración estatal moderna con sus instituciones centrales más fuertes y con un monarca con tendencias absolutistas, con un orden social y político tradicional y feudal, apoyándose en sus privilegios antiguos. El hecho que los Estados se basaran en las disposiciones de la Alegre Entrada, y defendieran con firmeza los privilegios, reforzó el duque de Alba en su convicción de que los Estados "querían poner el monarca bajo tutela"45.

Este artículo nos demuestra como el respeto de los privilegios era muy sensible, tanto en Brabante como en el resto de los Países Bajos. Por lo tanto, tanto el rey como los gobernadores manifestaron con frecuencia que no querían nada más que respeto por los privilegios. Sin embargo, esas declaraciones no pudieron convencer a la oposición leal, ni a los rebeldes y cada grupo tomó su propio camino: los unos se reconciliaron con el rey, y los otros siguieron su lucha hacia la independencia.

Tanto la oposición leal como los rebeldes reclamaron fuerte y explícitamente las antiguas libertades. Los dos grupos de provincias, que también estaban ligadas por alianzas, a finales del siglo XVI tomaron su propio camino, y en 1648 la República de los Países Bajos Unidos fue reconocida como estado independiente. Mientras, los Países Bajos meridionales o católicos quedaron unidos con la corona Habsburgo, pero nunca conocieron ningún gobierno absolutista. Esto se debe, en mi opinión, principalmente al hecho que siempre continuaron defendiendo sus privilegios ${ }^{46}$.

\footnotetext{
44 Mout, "Van arm vaderland", p. 357.

45 Janssens, "Brabant in het Verweer", pp. 178-179.

46 Después de la redacción de nuesto texto ha aparecido el artículo muy interesante del profesor Alastair Duke, "The use of 'privileges' in political discourse in the early modern Low Countries", Parliaments, Estates and Representation, 37 (2017; 1), p. 17-31. Lo siento que no he podido incorporar los resultados del profesor Duke en nuestra contribución.
} 
Bibliografía:

Christyn 1664: Jan Baptiste Christyn, Placcaeten, ordonnantien, landtcharters, privilegien, ende instructien by de Princen van dese Neder-Landen uytghegheven (...) (Bruselas: Huybrecht Antoon Velpius, 1664), vol. III.

Correspondance 1881: Correspondance du Cardinal de Granvelle, 15651583. ed. Edouard Poullet, 3, (Bruselas: Commission royale d'Histoire, 1881).

De la Fontaine Verwey 1960: Herman De la Fontaine Verwey, "De Blijde Inkomste en de opstand tegen Filips II", Standen en Landen -Anciens Pays et Assemblées d'États, 19, (1960), pp. 95-120.

De Vrankrijker 1933: Adrianus Clemens Johannes De Vrankrijker, De motiveering van onzen opstand. De theorieën van het verzet der Nederlandsche opstandelingen tegen Spanje in de jaren 1565-1581, (Nimega-Utrecht: Dekker \& van de Vegt, 1933).

De Vrankrijker 1936: Adrianus Clemens Johannes De Vrankrijker, "Het beroep op de Blyde Inkomste en andere privileges in Brabant tegen de inquisitie en de nieuwe bisdommen in de XVIe eeuw", Historisch Tijdschrift, 15, (1936), pp. 101-137.

Dierickx 1950: Michel Dierickx, De oprichting van de nieuwe bisdommen in de Nederlanden onder Filips II (1559-1570), (Amberes-Utrecht: Uitgeverij Standaard Boekhandel-Het Spectrum, 1950).

Dierickx 1963-1964: Michel Dierickx, "Nieuwe gegevens over het bestuur van de hertog van Alva in de Nederlanden", Bijdragen tot de Geschiedenis der Nederlanden, 18, (1963-1964), pp. 167-192.

Gachard 1861: Correspondance de Philippe II sur les affaires des Pays-Bas, ed. Louis-Prosper Gachard, (Bruselas: C. Muquardt, 1861).

Geurts 1958: Pieter Antoon Marie Geurts, "Het beroep op de Blijde Inkomste in de pamfletten uit de Tachtigjarige Oorlog", Standen en Landen - Ancien Pays et Assemblées d'État, 16, (1958), pp. 3-15.

Geurts 1978: Pieter Antoon Marie Geurts, De Nederlandse Opstand in de pamfletten 1566-1584, (Utrecht: HES Publishers, 1978).

Goosens 1997: Aline Goosens, Les inquisitions modernes dans les Pays-Bas méridionaux 1520-1633, (Bruselas: Éditions de I' Université de Bruxelles, 1997), 2 vols. 
Gorissen 1953: Pieter Gorissen, De prelaten van Brabant onder Karel $V$ (1515-1544). Hun confederatie (1534-1544). Standen en Landen - Anciens Pays et Assemblées d'États, 6, (Lovaina: Nauwelaerts, 1953).

Grapperhaus 1982: Ferdinand Grapperhaus, Alva en de Tiende Penning, (Zutphen: De Walburg Pers-Kluwer, 1982).

Grapperhaus 2006: Ferdinand Grapperhaus, "El décimo de Alba en los Países Bajos. Un fracaso de importantes consecuencias", en Banca, Crédito y capital. La Monarquía Hispana y los antiguos Países Bajos (1505-1700). comp. Carmen Sanz Ayán y Bernardo J. García García, (Madrid: Fundación Carlos de Amberes, 2006), pp. 105-180.

Iterson 1957: Willem Van Iterson, Geschiedenis der confiscatie in Nederland. Een rechtshistorische studie aan de hand van Noord-Nederlandse, een aantal Zuid-Nederlandse en andere bronnen, (Utrecht: De Vroede, 1957).

Janssens 1989: Gustaaf Janssens, 'Brabant in het Verweer'. Loyale oppositie tegen Spanje's bewind in de Nederlanden van Alva tot Farnese. 1567-1578. Standen en Landen-Anciens Pays et Assemblées d'États, 89, (Kortrijk-Heule: UGA, 1989).

Janssens 2008: Gustaaf Janssens, "De Tiende Penning van Alva: factor van goed bestuur en catalysator van verzet en opstand in de Nederlanden", Eigen Schoon \& De Brabander, 91, (2008), pp. 17-50.

Janssens 2009: Gustaaf Janssens, "De ordonnantie betreffende de pacificatie van de beroerten te Antwerpen (24 mei 1567): breekpunt voor de politiek van Filips II ten overstaan van de Nederlanden", Handelingen van de Koninklijke Commissie voor de uitgave der Oude Wetten en Verordeningen van België- Bulletin [de la] Commission royale pour la Publication des anciennes Lois et Ordonnances de Belgique, 50, (2009), pp. 105-132.

Janssens 2013: Gustaaf Janssens, "The Duke of Alba: Governor of the Netherlands in Times of War", en Alba. General and Servant to the Crown. comps. Maurits Ebben, Margriet Lacy-Bruijn, y Rolof van Hövelle tot Westerflier, (Rotterdam: Karawansaray Publishers, 2013), pp. 90-115.

Koenigsberger 2001: Helmut Georg Koenigsberger, Monarchies, States Generals and Parliaments. The Netherlands in the Fifteenth and Sixteenth Centuries, (Cambridge: University Press, 2001).

Mout 1986: Nicolette Mout, "Van arm vaderland tot eendrachtige republiek. De rol van politieke theorieën in de Nederlandse Opstand", Bijdragen en Mededelingen betreffende de Geschiedenis der Nederlanden, 101, (1986), pp. 345-365. 
Nierop 2001: Henk Van Nierop, "Alva's Throne: Making Sense of the Revolt of the Netherlands", en The Origins and Development of the Dutch Revolt, comp. Graham Darby, (Londres-Nueva York: Routledge, 2001), pp. 29-47.

Parker 1989: Geoffrey Parker, España y la rebelión de Flandes, (Madrid: Nerea, 1989).

Schenk 1933: Verantwoordinge, verklaringhe ende waerschouwinghe mitsgaders eene hertgrondighe begheerte des edelen, lancmoedighen ende hooghgeboren Princen van Oraengien. Naar de eerste drukken van 1568 opnieuw uitgegeven. ed. Magdalena Geertruida Schenk, (Amsterdam: Wereldbibliotheek, 1933).

Soen 2012: Violet Soen, Vredehandel. Adellijke en Habsburgse verzoeningspogingen tijdens de Nederlandse Opstand (1564-1581), (Amsterdam: Amsterdam University Press, 2012).

Stensland 2012: Monica Stensland, Habsburg Communication in the Dutch Revolt, (Amsterdam: Amsterdam University Press, 2012).

Tracy 1992: James D. Tracy, "Heresy Laws and centralization under Mary of Hungary: Conflict between the Council of Holland and the Central Government over the Enforcement of Charles V's Placards", Archiv für Reformationsgeschichte, 73, (1982), pp. 284-308.

Vrugt 1978: Marijke Van der Vrugt, De crimineleordonnantiën van 1570. Enkele beschouwingen over de eerste strafrechtcodificatie in de Nederlanden (Zutphen: De Walburg Pers, 1978).

Weis 2004: Monique Weis, Philippe de Marnix et le Saint-Empire (15661578). Les connections allemandes d'un porte-parole et la révolte des PaysBas, Collection des Études historiques, 10 (Bruselas: Société royale d'Histoire du Protestantisme belge, 2004). 